\title{
Prefrontal Oscillations during Recall of Conditioned and Extinguished Fear in Humans
}

\author{
Erik M. Mueller, ${ }^{1,2}$ Christian Panitz, ${ }^{1}$ Christiane Hermann, ${ }^{1}$ and Diego A. Pizzagalli ${ }^{2}$ \\ ${ }^{1}$ Department of Clinical Psychology, Justus-Liebig University Giessen, 35394 Giessen, Germany, and ${ }^{2}$ Center for Depression, Anxiety and Stress Research \& \\ McLean Imaging Center, McLean Hospital, Harvard Medical School, Belmont, Massachusetts 02478
}

\begin{abstract}
Human neuroimaging studies indicate that the anterior midcingulate cortex (AMC) and the ventromedial prefrontal cortex (vmPFC) play important roles in the expression and extinction of fear, respectively. Electrophysiological rodent studies further indicate that oscillatory neuronal activity in homolog regions (i.e., prelimbic and infralimbic cortices) changes during fear expression and fear extinction recall. Whether similar processes occur in humans remains largely unexplored. By assessing scalp surface EEG in conjunction with LORETA source estimation of CS-related theta and gamma activity, we tested whether a priori defined ROIs in the human AMC and vmPFC similarly modulate their oscillatory activity during fear expression and extinction recall, respectively. To this end, 42 healthy individuals underwent a differential conditioning/differential extinction protocol with a Recall Test on the next day. In the Recall Test, nonextinguished versus extinguished stimuli evoked an increased differential $\left(\mathrm{CS}^{+}\right.$vs $\mathrm{CS}^{-}$) response with regard to skin conductance and AMC-localized theta power. Conversely, extinguished versus nonextinguished stimuli evoked an increased differential response with regard to vmPFC-localized gamma power. Finally, individuals who failed to show a suppressed skin conductance response to the extinguished versus nonextinguished $\mathrm{CS}^{+}$also failed to show the otherwise observed alterations in vmPFC gamma power to extinguished $\mathrm{CS}^{+}$. These results indicate that fear expression is associated with AMC theta activity, whereas successful fear extinction recall relates to changes in vmPFC gamma activity. The present work thereby bridges findings from prior rodent electrophysiological research and human neuroimaging studies and indicates that EEG is a valuable tool for future fear extinction research.
\end{abstract}

Key words: conditioning; extinction; fear; theta

\section{Introduction}

Investigating how human brains retrieve previously conditioned and extinguished fear is critical for understanding anxiety (Myers and Davis, 2007; Norberg et al., 2008). Human neuroimaging studies suggest that the recall of conditioned and extinguished fear involves the anterior midcingulate cortex (AMC) and the ventromedial prefrontal cortex (vmPFC), respectively (Etkin et al., 2011; Milad and Quirk, 2012). Specifically, the AMC shows stronger activation to fear-conditioned versus nonconditioned stimuli (Büchel et al., 1998; Knight et al., 2004; Phelps et al., 2004; Milad et al., 2007a). Conversely, the vmPFC is more active when previously extinguished versus nonextinguished fear stimuli are presented after extinction (e.g. 24 h later) (Kalisch et al., 2006; Milad et al., 2007b), consistent with a critical role of vmPFC in

Received Aug. 9, 2013; revised March 31, 2014; accepted April 2, 2014.

Author contributions: E.M.M. designed research; E.M.M. performed research; E.M.M. contributed unpublished reagents/analytic tools; E.M.M., C.P., and D.A.P. analyzed data; E.M.M., C.H., and D.A.P. wrote the paper.

This work was supported by Deutsche Forschungsgemeinschaft Grant DFG MU3535/2-1 to E.M.M. and a Gustav A. Lienert stipend to E.M.M. We thank Hannah Münch, Anika Schulze, and Wiebke Schröter who collected the data as part of their theses.

Over the last 3 years, D.A.P. has received consulting fees from AstraZeneca, Pfizer, Shire, Servier, and Ono Pharma for studies unrelated to this project. The remaining authors declare no competing financial interests.

Correspondence should be addressed to Dr. Erik M. Mueller, Department of Clinical Psychology, Justus-Liebig University Giessen, 0tto-Behaghel Str. 10F, 39354 Giessen, Germany. E-mail: erik.mueller@psychol.uni-giessen.de. DOI:10.1523/JNEUROSCI.3427-13.2014

Copyright $\odot 2014$ the authors $\quad 0270-6474 / 14 / 347059-08 \$ 15.00 / 0$ fear extinction recall (Phelps et al., 2004; Quirk and Mueller, 2008).

In rodents, neurons in prelimbic cortex (a homolog region of human AMC) (Milad and Quirk, 2012) respond to previously fear-conditioned, nonextinguished stimuli with a sustained shift from $2 \mathrm{~Hz}$ to $\sim 4-8 \mathrm{~Hz}$ (Burgos-Robles et al., 2009), whereas neurons in the infralimbic cortex (a homolog region of vmPFC) (Milad and Quirk, 2012) switch to even higher frequencies during the presentation of previously extinguished fear stimuli (Milad and Quirk, 2002). Moreover, electrical stimulations of prelimbic and infralimbic neurons increase and decrease conditioned fear, respectively, suggesting that high-frequency activity in medial frontal cortices plays a causal role in the expression and suppression of fear (Milad and Quirk, 2002; Vidal-Gonzalez et al., 2006).

Whether prefrontal cortex oscillations change during the recall of conditioned and extinguished fear in humans is currently unknown. Notably, whereas the human AMC generates theta oscillations (e.g., 4-8 Hz) (Mueller et al., 2011), a relevant frequency range for fear expression in animals (Seidenbecher et al., 2003; Adhikari et al., 2010; Lesting et al., 2011), the vmPFC has been linked to the gamma rhythm (e.g., 36.5-44 Hz) (Pizzagalli et al., 2006; Mantini et al., 2007). Thus, we expect that retrieval of conditioned fear will relate to AMC theta activity (Hypothesis 1), whereas fear-extinction recall will relate to vmPFC gamma activity (Hypothesis 2). Although prior EEG studies on fear learning 
have focused on event-related potentials (Pizzagalli et al., 2003), fear-enhanced sensory processes (Miskovic and Keil, 2012), and single-session learning (Flor et al., 1996), none has probed oscillatory activity during retrieval of previously conditioned/extinguished fear.

Here, participants underwent a two-day differential fear conditioning and extinction paradigm (see Fig. 1). During acquisition, two stimuli were fear conditioned (CS + E and CS + N) and two were not $(\mathrm{CS}-\mathrm{E}$ and $\mathrm{CS}-\mathrm{N})$. During subsequent extinction, $\mathrm{CS}+\mathrm{E}$ and $\mathrm{CS}-\mathrm{E}$ were extinguished (i.e., presented without the US). To dissociate recall of conditioned and extinguished fear, CS + N and CS - N were not extinguished. Finally, all four CS were presented and EEG was recorded during a Recall Test on the next day. Low Resolution Electromagnetic Tomography (LORETA) (Pascual-Marqui et al., 1999) analysis was performed on day 2 CS-related EEG to probe whether AMC theta and vmPFC gamma during CS presentation differed as a function of day 1 learning and extinction history.

\section{Materials and Methods}

Participants. A total of $N=42$ subjects participated in the present study. Data were initially collected in two cohorts (A and B) with slightly varying experimental procedures (see below). Cohorts A and B consisted of $N=22$ (mean age: 21.1 years, SD: 1.4 years, 11 males) and $N=20$ (mean age: 25.0 years, SD: 3.7 years; 9 males; all right-handed and white) psychology students, respectively, who participated for partial fulfillment of course credit. After confirming that the central effects of the present study were not modulated by cohorts, both datasets were combined to increase statistical power. The study was approved by the local ethics committee of Marburg University Psychology Department.

Experimental paradigm. The two-day paradigm consisted of the four stages: Habituation (day 1), Acquisition (day 1), Extinction (day 1), and Extinction Recall (day 2). During Habituation, each CS was presented alone 5 times for $4 \mathrm{~s}$ with a jittered interstimulus interval of $6-8 \mathrm{~s}$. The Acquisition consisted of three blocks in each of which every CS was presented 20 times in random order. The $\mathrm{CS}^{+}$co-terminated with the US in $50 \%$ of the trials. In the Extinction phase (day 1), only one $\mathrm{CS}^{+}$("CS $+\mathrm{E}$ ") and one $\mathrm{CS}^{-}$("CS - E") were presented 40 times and a novel face ("Dummy Stimulus") was presented 20 times to maintain some variability in the presented stimuli. One $\mathrm{CS}^{+}$("CS $\left.+\mathrm{N}^{\prime}\right)$, one $\mathrm{CS}^{-}$("CS - N"), and the US were never presented during the Extinction phase. Finally, Recall Test (day 2) was identical to the Acquisition stage with the exception that the US was not presented (i.e., all CS were presented again). In Cohort B, the Extinction phase differed such that CS + E, CS - E, and the dummy stimulus were only presented 30, 30, and 15 times, respectively. In addition, throughout all phases, participants of Cohort B had to respond to randomly occurring arrows pointing to the left or right with an associated button press. This secondary task was included to ensure that participants attended to the screen throughout the experiment.

The CS stimuli consisted of four male faces with a neutral expression (Ekman and Friesen, 1976). The faces were black and white and presented in front of a black background with a size of $8.5 \times 11.5 \mathrm{~cm}$ (Cohort A) and $17 \times 22 \mathrm{~cm}$ (Cohort B). The specific assignment (i.e., CS + E, CS $+\mathrm{N}, \mathrm{CS}-\mathrm{E}, \mathrm{CS}-\mathrm{N}$; see below) of the CS was counterbalanced across face stimuli. The US consisted of a loud $85 \mathrm{~dB} 1000 \mathrm{~ms}$ white noise burst delivered over room speakers. If participants felt that the $85 \mathrm{~dB}$ burst was too loud, the US intensity was adapted such that it was perceived as "highly annoying but not painful."

Affective ratings. Participants rated each CS with respect to its associated valence and arousal on a 5 point Likert scale. In the Acquisition and Recall Test stage, all four CS were rated; in the Extinction stage, only CS $+\mathrm{E}$ and CS - E were rated. Ratings were given after each block (Cohort A) or after each stage (Cohorts A and B). To test for effective acquisition on day 1, the ratings after the Acquisition phase were analyzed. Effective extinction was probed by comparing CS + E versus CS - E ratings after the Acquisition phase with CS + E versus CS - E ratings after the Ex- tinction phase. Extinction and conditioning recall were assessed with Block 1 ratings of the day 2 Recall Test.

Skin conductance. Skin conductance was measured with an extra channel of the BioSemi ActiveTwo EEG system (see below) using two electrodes applied to the middle phalanges of the nondominant hand. Skin conductance was manually screened for artifacts, and the peak response in a window from 1 to $5 \mathrm{~s}$ relative to the CS onset was automatically determined for each trial. Skin conductance responses were then normalized by dividing by the subject's maximum overall response across conditions (Lykken and Venables, 1971) and averaged across trials by CS type. For two participants, skin conductance recordings were unavailable because of malfunctioning electrodes.

EEG recording and source localization. EEG was recorded during the day 2 Recall Test using a 64-channel BioSemi ActiveTwo EEG system with Driving Right Leg and Common Mode Sense as reference electrodes (for Cohort A, EEG was also recorded on day 1). EEG was rereferenced to the average reference, filtered using a $0.5 \mathrm{~Hz}$ low-pass filter, eye-blink corrected using Independent Component Analysis with manual rejection of clear eye-blink related components, manually screened for artifacts, and segmented into epochs ranging from 0 to $2 \mathrm{~s}$ relative to CS onset (Milad and Quirk, 2002). Using the LORETA software, these epochs were then subjected to standard spectral analyses via Discrete Fourier Transform using a boxcar windowing (Brillinger, 1981), yielding cross spectra with a resolution of $0.5 \mathrm{~Hz}$.

Next, for each frequency bin within the theta $(4-8 \mathrm{~Hz})$ (Mueller et al., 2011) and gamma (36.5-44 Hz) (Pizzagalli et al., 2006) range, intracerebral current density was computed using the LORETA algorithm across 2394 voxels constrained to cortical gray matter and hippocampi (Pascual-Marqui et al., 1994, 1999). LORETA finds a unique inverse solution for the cortical sources of the current pattern at the scalp level by assuming that neighboring neurons are activated synchronously and therefore produce smooth spatial distributions of intracerebral electrical activity. Although the validity of this distributed source localization technique has been supported from studies combining LORETA with fMRI (Vitacco et al., 2002; Mulert et al., 2004), PET (Pizzagalli et al., 2004), and intracranial recordings (Zumsteg et al., 2005), it is important to acknowledge the limitations of this method, including its limited spatial resolution. Next, using custom-made MATLAB (MathWorks) scripts, the estimated single-trial current density at each voxel was normalized such that the total activation across all voxels amounted to 1 for both EEG bands and averaged across all trials of one CS type to achieve CSassociated brain activation maps.

$\mathrm{AMC}$ and vmPFC ROIs were identified as the peak activation reported by Phelps et al. (2004) for the $\mathrm{CS}^{+}$versus $\mathrm{CS}^{-}$contrast on day 2 fear expression (AMC Talairach coordinates: $0,19,30$ ) and the peak activation in vmPFC reported by Milad et al. (2007b) for the CS + E versus CS $+\mathrm{N}$ contrast (vmPFC Talairach coordinates: $2,35,-8$ ). For statistical analyses, current density for AMC and vmPFC was extracted from the nearest corresponding voxels in LORETA space (AMC Talairach coordinates: $-3,17,29$; LORETA voxel \#1645; vmPFC Talairach coordinates: 4, 38, - 6; LORETA voxel \#778). For display purposes, activation values in the ROIs were scaled by the factor $1,000,000$.

In addition to analyses at the source level, scalp EEG spectral power was also assessed by FFT of the first and the second hamming-windowed $1000 \mathrm{~ms}$ relative to CS onset. These separate 1-s epochs allowed us to further explore whether CS-related oscillatory activity changed throughout the 2-s analysis window. The same theta and gamma ranges as in the source analyses were considered for the scalp data. In addition, at a reviewer's request, the frequency ranges from 30 to $43 \mathrm{~Hz}$ and from 65 to $80 \mathrm{~Hz}$ were explored. As shown in Figure 2, CS-related $\theta$ and $\gamma$ activity (collapsed across conditions) was maximal at frontal midline channel $\mathrm{Fz}$ and right frontopolar channel AF8, respectively. Scalp $\theta$ was therefore measured at channel $\mathrm{Fz}$ and neighboring channels $\mathrm{FCz}$ and $\mathrm{AFz}$, whereas gamma was measured at AF8 and neighboring channels Fp2 and F8.

Statistical analysis. The central hypotheses were all tested using repeated-measures ANOVAs with contingency $\left(\mathrm{CS}^{+}\right.$vs $\left.^{-}{ }^{-}\right)$and extinction (E vs $\mathrm{N}$ ) as repeated measure factors; the Greenhouse-Geisser correction was used where applicable. To confirm day 1 extinction of the differential response to CS + E vs CS $-\mathrm{E}$, a repeated-measures ANOVA 

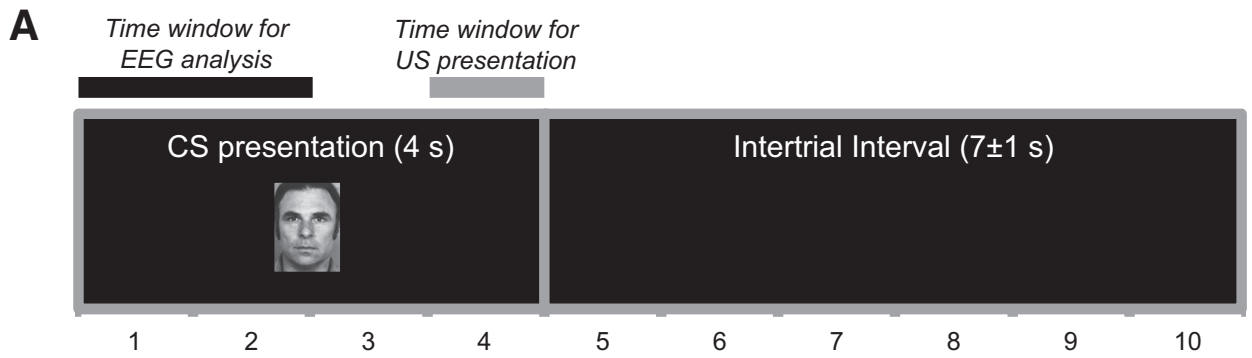

Time (s)

B

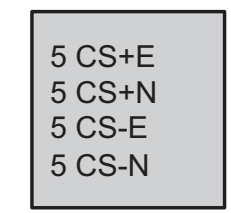

Habituation
Day 1

$60 \mathrm{CS}+\mathrm{E}$ w/ $30 \mathrm{US}$

$60 \mathrm{CS}+\mathrm{N}$ w/ $30 \mathrm{US}$

60 CS-E w/o US

\section{CS-N w/o US}

Acquisition
I Day 2

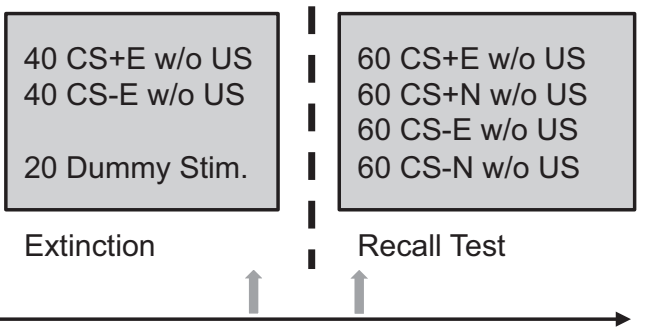

$40 \mathrm{CS}+\mathrm{E}$ w/o US I $60 \mathrm{CS}+\mathrm{E}$ w/o US

40 CS-E w/o US

20 Dummy Stim.

Time

C

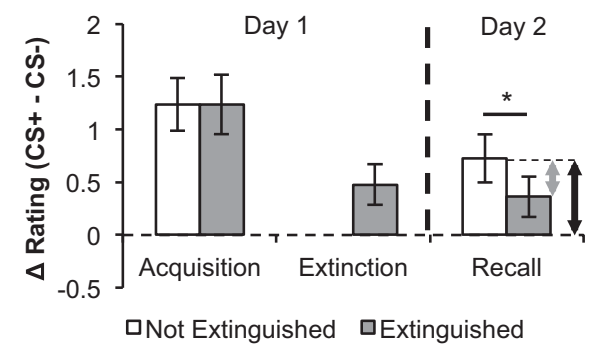

D Negative Valence (CS+ vs. CS-)

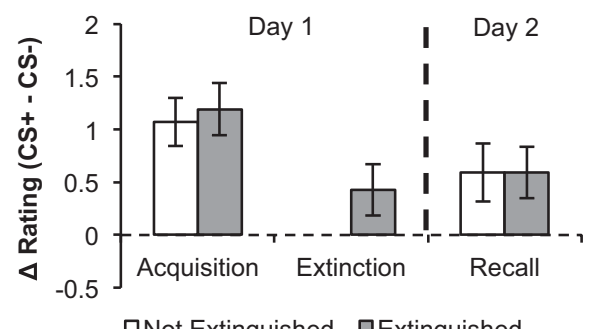

Figure 1. Paradigm used in the present study. $A$, Timeline for a single trial. The CS was presented for 4 s followed by a $6-8$ s intertrial interval. The time window for EEG analyses (black horizontal line) and US presentation (gray horizontal line) is also indicated. $\boldsymbol{B}$, Timeline of the four task phases for day 1 and 2 , and summary of the number and type of stimuli presented during each phase. $C S+E / C S-E, C S$ presented during extinction; $C S+N / C S-N$, $C S$ not presented during extinction. Gray vertical arrows indicate when the arousal and valence ratings provided in $\boldsymbol{C}$ and $\boldsymbol{D}$, respectively, were taken. $\boldsymbol{C}, \boldsymbol{D}$, Mean (SEM) differential $\left(C S^{+}-C S^{-}\right)$ratings of arousal $(\boldsymbol{C})$ and negative valence $(\boldsymbol{D})$ for stimuli that were presented during the Extinction phase (gray bars) or those that were not presented (white bars). Ratings were provided on a 5 point Likert scale. $C$, The black vertical arrow indicates the amount of conditioned fear recall (i.e., $C S+N-C S-N ; p<0.005$ ). The gray vertical arrow indicates the amount of fear extinction recall (i.e., conditioned fear recall of nonextinguished as opposed to extinguished (S pairs; $p<0.02) .{ }^{*} p<0.05$.

with contingency (CS + E vs CS - E) and stage (before vs after extinction) was conducted on the affective ratings. Tests on brain activity focused on LORETA-estimated current density in two a priori defined ROIs, and the $\alpha$-level was set to 0.05 . For tests on whole-brain LORETA activation, tetrad extinction recall (ER) scores were computed for each $\operatorname{voxel}(\mathrm{ER}=[\mathrm{CS}+\mathrm{N}-\mathrm{CS}-\mathrm{N}]-[\mathrm{CS}+\mathrm{E}-\mathrm{CS}-\mathrm{E}])$. If this score deviates from 0 , the differential fear responses (i.e., $\mathrm{CS}^{+}$vs $\mathrm{CS}^{-}$) are different for stimuli that had or had not been extinguished $24 \mathrm{~h}$ before. However, more positive ER values may result from both increased activity to $\mathrm{CS}+\mathrm{N}$ versus $\mathrm{CS}-\mathrm{N}$ and/or reduced activity to $\mathrm{CS}+\mathrm{E}$ versus CS - E. Because the main purpose of the whole-brain LORETA analyses was to show that the reported effects were specific to the predefined ROIs, the threshold was set to $p<0.05$ without correcting for multiple comparisons. Finally, in addition to extinction and contingency, ANOVAs on scalp EEG spectral power also included the factors electrode and time window $(0-1000$ vs $1000-2000 \mathrm{~ms})$.

\section{Results}

Affective ratings

As shown in Figure $1 C, D$, ratings collected directly after acquisition demonstrated successful conditioning, with the $\mathrm{CS}^{+}$rated as more arousing (main effect contingency: $F_{(1,41)}=24.64, p<$ $0.0001)$ and unpleasant $\left(F_{(1,41)}=9.16, p<0.005\right)$ than the $\mathrm{CS}^{-}$. There was no main effect or interaction involving extinction, confirming that $\mathrm{CS}+\mathrm{E}$ and $\mathrm{CS}+\mathrm{N}$ were associated with equal levels of arousal (CS + E: $2.98 \pm 1.26$; CS $+\mathrm{N}: 2.93 \pm 1.23)$ and negative versus positive valence (CS $+\mathrm{E}: 2.24 \pm 0.93$; $\mathrm{CS}+\mathrm{N}$ : $2.14 \pm 1.09)$ before extinction $(p>0.5)$. After the Extinction stage, the extinguished CS + E (compared with the CS - E) was rated as relatively less arousing and negatively valenced than before the Extinction stage, thereby confirming effective day 1 extinction (contingency $\times$ time interaction, arousal: $F_{(1,41)}=$ 10.03, $p<0.005$; valence: $\left.F_{(1,41)}=15.71, p<0.0005\right)$.

Most importantly, the day 2 Recall Test arousal ratings revealed that day 1 conditioning and extinction were successfully recalled (contingency $\times$ extinction interaction: $F_{(1,21)}=6.72$, $p<0.018)$. As expected, ratings were significantly higher for CS $+\mathrm{N}(2.45 \pm 0.22)$ versus $\mathrm{CS}-\mathrm{N}\left(1.72 \pm 0.16 ; t_{(21)}=3.17, p<\right.$ $0.005)$, which is consistent with successful recall of conditioned, nonextinguished fear. Conversely, arousal ratings were not sig- 


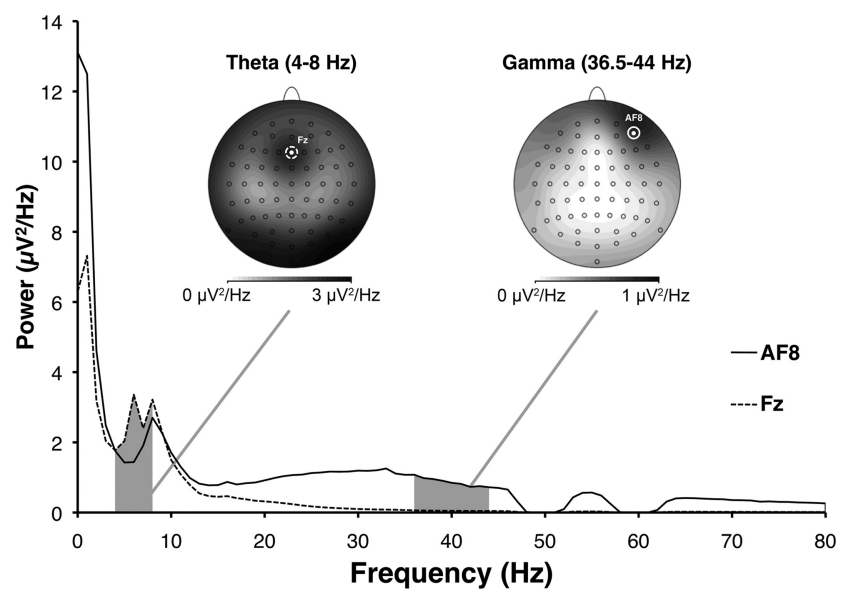

Figure 2. Power spectrum for EEG from 0 to $2000 \mathrm{~ms}$ after CS onset (collapsed across different CS types) at sensor $\mathrm{Fz}$ and AF8, where theta ( $4-8 \mathrm{~Hz}$, left gray-shaded area) and gamma (36.5- $44 \mathrm{~Hz}$, right gray-shaded area) power was maximal, respectively. The scalp topography of CS-related theta (left) and gamma (right) power is also shown.

nificantly different between CS $+\mathrm{E}(2.18 \pm 0.20)$ and CS $-\mathrm{E}$ $\left(1.8 \pm 0.19 ; t_{(21)}=1.89, p=0.07\right)$, consistent with successful recall of extinguished fear. Main effects of contingency further indicate that $\mathrm{CS}^{+}$were generally perceived as more arousing $\left(F_{(1,21)}=7.45, p<0.02\right)$ and unpleasant $\left(F_{(1,21)}=6.25, p<0.02\right)$ than $\mathrm{CS}^{-}$.

\section{Physiological assessment of fear conditioning recall and extinction recall}

Like the arousal ratings, day 2 SCR amplitudes confirmed successful recall of both fear conditioning and extinction (contingency $\times$ extinction interaction: $\left(F_{(1,39)}=8.66, p<0.006\right)$. Specifically, CS $+\mathrm{N}(0.051 \pm 0.006)$ produced significantly larger SCRs than the CS $-\mathrm{N}\left(0.038 \pm 0.005 ; t_{(38)}=3.11, p<\right.$ $0.005)$, consistent with successful fear conditioning consolidation and recall. Critically, the CS $+\mathrm{E}(0.047 \pm 0.007)$ did not show a larger SCR compared with the CS $-\mathrm{E}(0.050 \pm 0.006 ; p>$ 0.6 ; Fig. $3 A$ ), indicating effective fear extinction recall.

\section{Prefrontal oscillations during fear conditioning recall and extinction recall}

Theta. AMC-localized theta power during the day 2 Recall Test was modulated by a significant contingency $\times$ extinction interaction $\left(F_{(1,41)}=8.87 ; p<0.005\right.$; Fig. $\left.3 B\right)$. Providing important evidence for Hypothesis 1 (involvement of AMC theta in fear expression), AMC theta was significantly larger for $\mathrm{CS}+\mathrm{N}$ $(22.7 \pm 0.95)$ relative to $\mathrm{CS}-\mathrm{N}\left(22.3 \pm 0.93 ; t_{(41)}=2.50, p<\right.$ $0.02)$, although there were no significant differences between CS $+\mathrm{E}(22.4 \pm 0.96)$ and $\mathrm{CS}-\mathrm{E}\left(22.6 \pm 0.95 ; t_{(41)}=1.00, p>0.3\right)$. Highlighting the specificity of these findings, there were no significant main effects or interactions for the vmPFC ROI in the theta frequency band $(p>0.1)$.

Converging with the findings at the AMC, analyses of frontal midline scalp channel EEG also revealed a significant contingency $\times$ extinction interaction $\left(F_{(1,41)}=5.22 ; p<0.03\right)$. Corroborating our choice of investigating 2-s epochs for the LORETA analyses, the contingency $\times$ extinction interaction in the scalp analyses was not further modulated by time window (i.e., whether theta was recorded from 0 to $1000 \mathrm{~ms}$ or 1000 to $2000 \mathrm{~ms}$ relative to CS onset: time window $\times$ contingency $\times$ extinction: $p>0.4$, partial eta squared: 0.01). As for AMC-localized theta, $\mathrm{CS}+\mathrm{N}$ minus $\mathrm{CS}-\mathrm{N}$ was larger than $\mathrm{CS}+\mathrm{E}$ minus $\mathrm{CS}-\mathrm{E}$.
Additional exploratory analyses were performed with the scalp channel EEG: First, analysis of scalp channel theta power from 2000 to $3000 \mathrm{~ms}$ after CS onset during the Recall Test revealed that the observed effect did not extend beyond the $2000 \mathrm{~ms}$ analysis window contingency $\times$ extinction interaction $(p>0.5)$. Second, we analyzed EEG data collected during acquisition (only available for Cohort A) and confirmed the absence of a significant contingency $\times$ extinction interaction before the Recall Test $\left(F_{(1,20)}=0.11, p>0.7\right.$, partial eta squared $\left.=0.005\right)$. Moreover, to test whether increased theta to nonextinguished $\mathrm{CS}^{+}$versus $\mathrm{CS}^{-}$ is specific for retrieval of conditioned fear (Hypothesis 1) and not related to general fear expression, we also compared $\mathrm{CS}^{+}$and $\mathrm{CS}^{-}$during the Acquisition and Extinction phase. Consistent with Hypothesis 1, none of these analyses revealed significant differences between $\mathrm{CS}^{+}$and $\mathrm{CS}^{-}(p>0.07)$.

Gamma. In line with Hypothesis 2 (involvement of vmPFC $\gamma$ in fear extinction recall), a contingency $\times$ extinction ANOVA on vmPFC-localized gamma current density also revealed a significant two-way interaction $\left(F_{(1,41)}=5.45, p<0.025\right.$; Fig. 3$)$. Unlike AMC theta, post hoc tests revealed that vmPFC gamma did not differ between CS $+\mathrm{N}(25.5 \pm 1.5)$ and CS $-\mathrm{N}(25.3 \pm 1.5$; $\left.t_{(41)}=0.86, p>0.3\right)$ but rather was reduced during $\mathrm{CS}+\mathrm{E}$ $(25.3 \pm 1.1)$ versus CS - E presentation $\left(25.8 \pm 1.6 ; t_{(41)}=2.45\right.$, $p<0.02)$, which is consistent with the hypothesized role of vmPFC in extinction recall rather than fear expression. There were no significant main effects or interactions for the AMC ROI in the gamma frequency band $(p>0.3)$.

Gamma power at the scalp level was not significantly modulated by contingency or extinction. Exploratory analyses for different time windows (i.e., 2-3 s after stimulus presentation) or gamma ranges (i.e., $30-43 \mathrm{~Hz}$; $65-80 \mathrm{~Hz}$ ) did not yield significant main effects or interactions $(p>0.3)$.

\section{Regional specificity of the ROI findings}

To confirm that the reported effects of theta and gamma activity were specific to AMC and vmPFC, respectively, we also tested for ER effects at the whole-brain level. For each voxel, frequency band, and participant, an ER score was computed and tested for significance across participants using an uncorrected $p$ value of 0.05 (see Experimental procedures). Despite the liberal criterion, significant ER scores were largely restricted to the AMC in the theta band (Fig. 3D) and vmPFC in the gamma band (Fig. 3E), thereby supporting the regional specificity of the ROI findings (Fig. 3). Additional regions with significant voxels are provided in Table 1. Of note, gamma ER scores significantly differed from 0 within the left hippocampus, a region previously implicated in fear extinction recall (Kalisch et al., 2006; Milad et al., 2007b).

\section{Relationships between electrodermal and electrocortical correlates of fear extinction}

Although the differential SCR response was reliably extinguished at the group level, it should be noted that only $n=23$ participants $(58 \%)$ showed a reduced SCR when directly comparing CS + E vs $\mathrm{CS}+\mathrm{N}$ responses, whereas this was not the case for a considerable number of participants $(n=17 ; 42 \%)$. This converges with prior reports of substantial between-subject variation in successful fear extinction recall and has potential relevance for the treatment of anxiety (Milad et al., 2009).

To further test whether fear extinction success was related to vmPFC activity (Milad et al., 2007b), we compared the 23 participants with successful SCR extinction with the 17 participants with failed SCR extinction. As shown in Figure 4, the successful SCR extinction group showed a very robust contingency $\times$ ex- 


\section{A Skin Conductance}

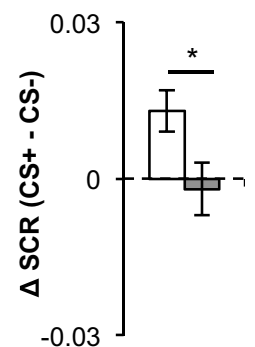

B Theta (AMC ROI)

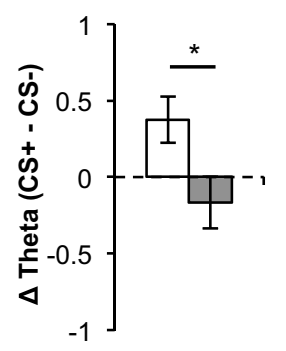

\section{Gamma (vmPFC ROI)}

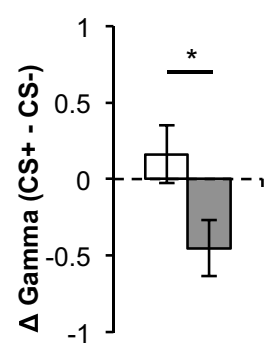

Not Extinguished

Extinguished

\section{Extinction Recall (Theta)}

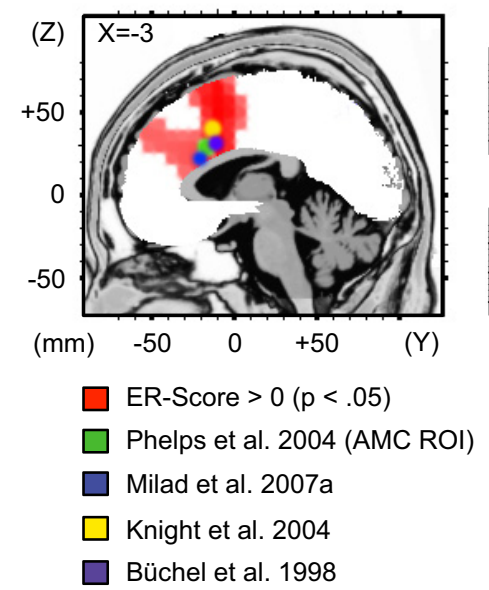

E Extinction Recall (Gamma)

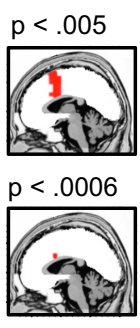

Figure 3. Bar plot indicating mean \pm SEM differential (i.e., $C S^{+}$vs $\left.\mathrm{CS}^{-}\right)$normalized skin conductance responses $(\boldsymbol{A})$, log-transformed theta current density in the $A M C$ ROI $(\boldsymbol{B})$, and log-transformed gamma current density in the vmPFC ROI (C) to stimuli that were either presented during extinction $24 \mathrm{~h}$ before (gray) or not (white). ${ }^{*}$ Differential responses (CS ${ }^{+}-C^{-}$) are significantly different from 0 (placed above/below bars) or significantly differ between extinguished and nonextinguished stimuli (placed between bars, $p<0.05$ ). $\boldsymbol{B}$, Bar graph represents that the significant contingency $\times$ extinction interaction at AMC is driven by significant CS ${ }^{+}$versus $\mathrm{CS}^{-}$differences for nonextinguished stimuli, which is consistent with a role of AMC in the retrieval of conditioned fear and/or fear expression. $C$, In contrast, bar graph represents that the contingency $\times$ extinction interaction at vmPFC is driven by significant $C S^{+}$versus $C S^{-}$differences for extinguished stimuli, which is consistent with a role of vmPFC in fear extinction recall. $\boldsymbol{D}$, Sagittal slice of LORETA standard brain at Talairach coordinate $X=-3$. All voxels where differential CS + vs $\mathrm{CS}^{-}$theta $(4-8 \mathrm{~Hz})$ current density on day 2 is significantly affected depending on day 1 extinction (i.e., ER score significantly $>0$ ) are indicated in red ( $p<0.05$, uncorrected). Green circle represents the AMC ROI used for the current ROl analyses, which was based on the comparison by Phelps et al. (2004) of CS ${ }^{+}$and CS ${ }^{-}$(peak voxel in Phelps et al., 2004). Regions of AMC peak differences between nonextinguished CS ${ }^{+}$and CS ${ }^{-}$for other previous fMRI studies are also indicated in blue (Milad et al., 2007a), yellow (Knight et al., 2004), and purple (Büchel et al., 1998). Small subplots of sagittal slices at coordinate $X=-3$ indicate significant ER scores thresholded at $p=0.005$ (top) and $p=0.0006$ (bottom; $p=0.0006$ is the smallest threshold that yields a significant voxel). $E$, Sagittal slice of LORETA standard brain at Talairach coordinate $X=4$. Red represents voxels where differential CS ${ }^{+}$versus CS ${ }^{-}$gamma (36.5-44 Hz) activity on day 2 is significantly affected depending on day 1 fear extinction (i.e., ER score significantly $>0, p<0.05$, uncorrected). Green circle represents vmPFC ROI used for the current ROI analyses, which was based on the peak voxel in the comparison by Milad et al. (2007a) of CS + E and CS + N. Regions of vmPFC peak activation of extinction-related CS ${ }^{+}$as reported in $\mathrm{fMRI}$ studies are also indicated in blue (Phelps et al., 2004) and yellow (Kalisch et al., 2006).

Table 1. Regions with significant extinction retention scores for $\theta$ and $\gamma$ LORETA estimated current density

\begin{tabular}{|c|c|c|c|c|c|}
\hline \multirow[b]{2}{*}{ Region } & \multicolumn{3}{|c|}{$\begin{array}{l}\text { Talairach } \\
\text { coordinates }\end{array}$} & \multirow{2}{*}{$\begin{array}{l}\text { Cluster } \\
\text { extent } \\
\text { (voxels } \\
p<0.05 \text { ) }\end{array}$} & \multirow{2}{*}{$\begin{array}{l}t \\
(\mathrm{df}=41)\end{array}$} \\
\hline & $X$ & $Y$ & Z & & \\
\hline \multicolumn{6}{|l|}{ Theta $(4-8 \mathrm{~Hz})$} \\
\hline Anterior midcingulate cortex & -3 & 10 & 29 & 138 & $3.72^{* * * *}$ \\
\hline Precuneus & -24 & -67 & 36 & 50 & $-3.28^{* * *}$ \\
\hline Superior temporal gyrus & -52 & -32 & 8 & 68 & $-3.22^{* * *}$ \\
\hline Inferior parietal lobule & -52 & -53 & 43 & 10 & $-2.61^{*}$ \\
\hline \multicolumn{6}{|l|}{ Gamma (36.5-44 Hz) } \\
\hline vmPFC (BA32) & -3 & 38 & 1 & 13 & $2.39 *$ \\
\hline Left hippocampus & -38 & -25 & -13 & 30 & $-2.79^{* *}$ \\
\hline Left inferior frontal gyrus (BA10) & -45 & 45 & 1 & 8 & $-2.39^{*}$ \\
\hline
\end{tabular}

tinction interaction on vmPFC gamma current density $\left(F_{(1,22)}=\right.$ $11.78, p<0.003$, partial eta square $=0.35)$, whereas this interaction was absent in the failed SCR extinction group $\left(F_{(1,16)}=0.40\right.$, $p>0.5$, partial eta square $=0.02$; group $\times$ contingency $\times$ extinction interaction: $\left.F_{(1,38)}=3.82, p<0.06\right)$.

\section{Discussion}

The overarching goal of this study was to elucidate neurophysiological mechanisms associated with the recall of conditioned and extinguished fear in humans using noninvasive EEG. Inspired by prior $\mathrm{fMRI}$ and rodent studies, we hypothesized that changes in AMC and vmPFC oscillatory activity would be associated with recall of conditioned and extinguished fear, respectively. We tested our hypotheses by using a two-day differential conditioning and differential extinction paradigm in conjunction with EEG and source localization. Consistent with our first hypothesis, we 


\section{Gamma (vmPFC ROI)}
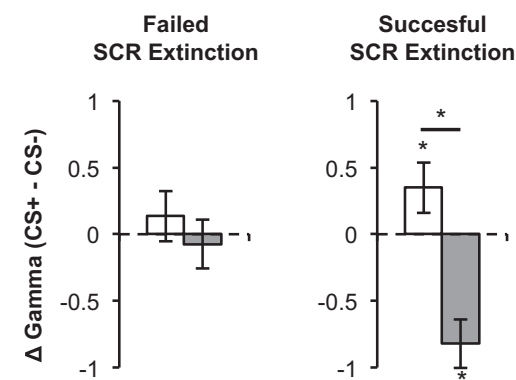

Figure 4. Bar graph showing the differential vmPFC gamma current density (CS ${ }^{+}$vs $\mathrm{CS}^{-}$) for not extinguished (white) and extinguished (gray) stimuli (see also Fig. 3B), separately plotted for individuals with successful fear extinction as measured with SCR (i.e., reduced SCR to extinguished vs nonextinguished $\mathrm{CS}^{+}$; right) and failed fear extinction (left). *Differential responses for a given condition are significantly different from 0 (placed above/below bars) or significantly different from another condition (placed between bars, $p<0.05$ ).

found that stimuli that had been fear conditioned and not extinguished on the previous day (i.e., CS $+\mathrm{N}$ ) evoked significantly more AMC-theta activity than not fear conditioned stimuli (i.e., CS $-\mathrm{N}$ ) in the day 2 Recall Test. Moreover, confirming our second hypothesis, fear stimuli that had been extinguished on the previous day (i.e., CS + E) elicited lower vmPFC gamma activity relative to nonfear stimuli that had been presented during extinction (i.e., CS - E). Thus, the present study shows, for the first time, that the retrieval of long-term conditioned and extinguished fear in humans is associated with changes in prefrontal cortex theta and gamma oscillatory activity.

Findings emerging in the context of the first hypothesis suggest that fear-evoking stimuli lead to increased theta activity in the AMC and thus converge with the following: (1) EEG studies showing that frontomedial theta is predominantly generated in the AMC (Asada et al., 1999; Ishii et al., 1999); (2) fMRI studies showing a predominant role of AMC in fear expression (for review, see: Vogt, 2005; Etkin et al., 2011; Milad and Quirk, 2012); and (3) animal studies indicating that (medial prefrontal) theta activity is highly relevant for fear expression (Seidenbecher et al., 2003; Pape et al., 2005; Burgos-Robles et al., 2009; Lesting et al., 2011; Narayanan et al., 2011). Together, these findings suggest that AMC theta may play an important role in human fear expression. This interpretation is further supported by the absence of AMC theta differences for extinguished $\mathrm{CS}^{+}$versus $\mathrm{CS}^{-}$, mirroring the attenuation of prelimbic theta enhancements after successful fear extinction in rats (Burgos-Robles et al., 2009).

The AMC receives afferents from the amygdala (Vogt and Pandya, 1987; Vogt, 2005), and theta oscillations may serve to retrieve episodic memories and communicate between brain regions (Klimesch, 1996), including medial prefrontal cortex and amygdala during fear processing (Lesting et al., 2011). As the rodent prelimbic cortex is important for sustaining an increased level of fear during ongoing threat presentation, which only evokes a transient amygdala response directly after stimulus onset (Burgos-Robles et al., 2009), the observed AMC theta response might reflect an extended state of anxious apprehension during the retrieval of threat-related memories. The human AMC is involved in a number of relevant processes (Shackman et al., 2011), including central control of the autonomic nervous systems (Critchley et al., 2003; Panitz et al., 2013) and may thereby regulate physiological fear responses. Consistent with this interpretation, SCR findings closely mirrored the pattern of AMC theta: Both were increased in response to $\mathrm{CS}+\mathrm{N}$ versus $\mathrm{CS}-\mathrm{N}$ but not to CS + E versus CS $-\mathrm{E}$. More generally, evoked frontomedial theta has been related to the processing of events that are worse than expected (Mueller et al., 2011; Cavanagh et al., 2012) and dispositional anxiety (Mueller et al., 2013). Together, $\mathrm{CS}+\mathrm{N}$-evoked AMC theta enhancements may indicate a number of mechanisms, including the retrieval of fear memories, regulation of physiological fear responses, or a general processing of any unpleasant events requiring adaptive control (Shackman et al., 2011). The functional relevance of the relationship between AMC theta and fear-related processing should be further investigated in future studies.

In contrast to AMC theta, vmPFC gamma was not affected by the presentation of nonextinguished $\mathrm{CS}^{+}$versus $\mathrm{CS}^{-}$, which is consistent with studies indicating that the vmPFC in humans and the infralimbic cortex in rodents are not responsive to fear stimuli per se (Etkin et al., 2011; Milad and Quirk, 2012). Instead, vmPFC gamma activity differed between extinguished $\mathrm{CS}^{+}$and $\mathrm{CS}^{-}$, which supports the following hypotheses: (1) a particular safety signal becomes associated with the $\mathrm{CS}^{+}$during extinction (Myers and Davis, 2007); (2) the retention and recall of this safety signal involve the vmPFC or infralimbic cortex (Milad and Quirk, 2012); and (3) the retention and recall of this safety signal involve fast oscillatory processes in the vmPFC/infralimbic cortex (Milad and Quirk, 2002). Gamma activity can only be measured on the scalp surface EEG when large numbers of neurons show coordinated activities (Jensen et al., 2007). Therefore, the current findings may reflect that larger cell assemblies change their gamma-range oscillation patterns during fear extinction recall, perhaps because more specific neuron populations in the vmPFC increase their firing rates in response to the CS + E (Milad and Quirk, 2002; Santini et al., 2008).

During extinction recall, the vmPFC presumably receives inputs from the hippocampus (Kalisch et al., 2006; Milad et al., 2007b). Notably, gamma ER scores at the whole-brain level were not only significant for the vmPFC but also for the hippocampus, indicating that both regions may be relevant for fear extinction recall. Both regions project to the amygdala (Milad et al., 2007b; Beckmann et al., 2009; Orsini et al., 2011) and may reduce amygdala-driven fear expression by activating inhibitory regions of the amygdala during extinction recall (McDonald, 1998; Orsini et al., 2011; Milad and Quirk, 2012). Moreover, the hippocampus may confer vmPFC-dependent fear extinction recall by coding for contextual information (Delamater, 2004; Kalisch et al., 2006) or directly gate fear expression after extinction by inhibiting fear signaling in AMC or rodent prelimbic cortex (Sotres-Bayon et al., 2012). Together, prior rodent and fMRI studies are thus consistent with the current finding of hippocampal gamma alterations during fear extinction recall, which, however, should be replicated in future EEG studies on hippocampal fear extinction recall mechanisms.

Further consistent with a role of vmPFC in fear reduction, participants who showed lower SCR responses to extinguished versus nonextinguished $\mathrm{CS}^{+}$were characterized by altered vmPFC gamma activity to the extinguished CSs, whereas this effect was absent in participants who failed to show reduced SCR to the $\mathrm{CS}+\mathrm{E}$ versus $\mathrm{CS}+\mathrm{N}$. This finding converges with human (Milad et al., 2007b) and animal (Milad and Quirk, 2002; BurgosRobles et al., 2007; Santini et al., 2008) studies suggesting that difficulties in successful fear extinction recall may be related to blunted vmPFC/infralimbic cortex recruitment. By further probing vmPFC EEG or fMRI activity in anxiety disorders (Milad et 
al., 2009), these findings might ultimately be related to moderators of long-term exposure therapy outcome.

The present study has some limitations. First, more trials than in most fear conditioning/extinction studies were used to achieve sufficient signal-to-noise ratio for EEG (but see Flor et al., 1996; Wessa and Flor, 2007). This may have facilitated habituation to the US and CS throughout the Acquisition, Extinction, and Recall phases. Moreover, because the US was no longer presented during the Recall phase, further within-session extinction presumably occurred on day 2 . However, ongoing habituation and extinction would have reduced conditioning- and/or extinctionrelated stimulus differences. Because the hypothesized contingency $X$ extinction interactions were nevertheless significant, the reported effects seem particularly strong. As a further limitation, amygdala activity cannot be probed using EEG and was therefore not investigated in the present study. In addition, because of the limited spatial resolution of EEG and LORETA, the current density extracted from the AMC and vmPFC ROIs was likely influenced by activity from neighboring regions. To more precisely localize the sources of the current AMC theta and vmPFC gamma effects and to test how they relate to amygdala activity, future studies that combine the present approach with fMRI will be needed. Finally, the signal of frontal gamma is relatively weak and can be affected by ocular activity to complex visual stimuli or muscular activity to noise bursts. Because the US was never presented during the Recall Test and because visual stimuli were counterbalanced across conditions, it is unlikely that such artifacts influenced the present findings. However, effects for gamma activity were weaker than for theta activity and did not emerge at frontopolar electrodes but only in the LORETA analyses. Although the precise localization of the gamma effect to the vmPFC supports its validity, future replications of the present effects in the gamma range are warranted.

Despite these limitations, the present study provides novel evidence that electrophysiological correlates of human fear conditioning and extinction recall can be probed noninvasively using EEG. More importantly, the present EEG findings clarify that human recall of conditioned and extinguished fear $24 \mathrm{~h}$ after a fear conditioning and extinction procedure involves the AMC and vmPFC, respectively, which contribute to integrate prior animal and fMRI studies. The present results further indicate that AMC-associated fear conditioning recall relates to theta oscillations, whereas vmPFC-associated extinction recall is linked to gamma activity. Future fear extinction studies may further exploit the advantages of EEG, which include the following: (1) high temporal resolution, which allows to adequately capture fearrelated oscillatory processes and cross-region interactions; (2) economic data collection of large samples required for molecular genetic research of anxiety risk factors; and (3) data collection in real life environments, including fear exposure therapy.

\section{References}

Adhikari A, Topiwala MA, Gordon JA (2010) Synchronized activity between the ventral hippocampus and the medial prefrontal cortex during anxiety. Neuron 65:257-269. CrossRef Medline

Asada H, Fukuda Y, Tsunoda S, Yamaguchi M, Tonoike M (1999) Frontal midline theta rhythms reflect alternative activation of prefrontal cortex and anterior cingulate cortex in humans. Neurosci Lett 274:29-32. CrossRef Medline

Beckmann M, Johansen-Berg H, Rushworth MF (2009) Connectivity-based parcellation of human cingulate cortex and its relation to functional specialization. J Neurosci 29:1175-1190. CrossRef Medline

Brillinger DR (1981) Time series: data analysis and theory. New York: McGraw-Hill.

Büchel C, Morris J, Dolan RJ, Friston KJ (1998) Brain systems mediating aversive conditioning: an event-related fMRI study. Neuron 20:947-957. CrossRef Medline

Burgos-Robles A, Vidal-Gonzalez I, Santini E, Quirk GJ (2007) Consolidation of fear extinction requires NMDA receptor-dependent bursting in the ventromedial prefrontal cortex. Neuron 53:871-880. CrossRef Medline

Burgos-Robles A, Vidal-Gonzalez I, Quirk GJ (2009) Sustained conditioned responses in prelimbic prefrontal neurons are correlated with fear expression and extinction failure. J Neurosci 29:8474-8482. CrossRef Medline

Cavanagh JF, Zambrano-Vazquez L, Allen JJ (2012) Theta lingua franca: a common mid-frontal substrate for action monitoring processes. Psychophysiology 49:220-238. CrossRef Medline

Critchley HD, Mathias CJ, Josephs O, O’Doherty J, Zanini S, Dewar BK, Cipolotti L, Shallice T, Dolan RJ (2003) Human cingulate cortex and autonomic control: converging neuroimaging and clinical evidence. Brain 126:2139-2152. CrossRef Medline

Delamater AR (2004) Experimental extinction in Pavlovian conditioning: behavioural and neuroscience perspectives. Q J Exp Psychol B 57:97-132. CrossRef Medline

Ekman P, Friesen WV (1976) Pictures of facial affect. Palo Alto, CA: Consulting Psychologists.

Etkin A, Egner T, Kalisch R (2011) Emotional processing in anterior cingulate and medial prefrontal cortex. Trends Cogn Sci 15:85-93. CrossRef Medline

Flor H, Birbaumer N, Roberts LE, Feige B, Lutzenberger W, Hermann C, Kopp B (1996) Slow potentials, event-related potentials, "gammaband" activity, and motor responses during aversive conditioning in humans. Exp Brain Res 112:298-312. Medline

Ishii R, Shinosaki K, Ukai S, Inouye T, Ishihara T, Yoshimine T, Hirabuki N, Asada H, Kihara T, Robinson SE, Takeda M (1999) Medial prefrontal cortex generates frontal midline theta rhythm. Neuroreport 10:675-679. CrossRef Medline

Jensen O, Kaiser J, Lachaux JP (2007) Human gamma-frequency oscillations associated with attention and memory. Trends Neurosci 30:317324. CrossRef Medline

Kalisch R, Korenfeld E, Stephan KE, Weiskopf N, Seymour B, Dolan RJ (2006) Context-dependent human extinction memory is mediated by a ventromedial prefrontal and hippocampal network. J Neurosci 26:95039511. CrossRef Medline

Klimesch W (1996) Memory processes, brain oscillations and EEG synchronization. Int J Psychophysiol 24:61-100. CrossRef Medline

Knight DC, Cheng DT, Smith CN, Stein EA, Helmstetter FJ (2004) Neural substrates mediating human delay and trace fear conditioning. J Neurosci 24:218-228. CrossRef Medline

Lesting J, Narayanan RT, Kluge C, Sangha S, Seidenbecher T, Pape HC (2011) Patterns of coupled theta activity in amygdala-hippocampalprefrontal cortical circuits during fear extinction. PLoS One 6:e21714. CrossRef Medline

Lykken DT, Venables PH (1971) Direct measurement of skin conductance: a proposal for standardization. Psychophysiology 8:656-672. CrossRef Medline

Mantini D, Perrucci MG, Del Gratta C, Romani GL, Corbetta M (2007) Electrophysiological signatures of resting state networks in the human brain. Proc Natl Acad Sci U S A 104:13170-13175. CrossRef Medline

McDonald AJ (1998) Cortical pathways to the mammalian amygdala. Prog Neurobiol 55:257-332. CrossRef Medline

Milad MR, Quirk GJ (2002) Neurons in medial prefrontal cortex signal memory for fear extinction. Nature 420:70-74. CrossRef Medline

Milad MR, Quirk GJ (2012) Fear extinction as a model for translational neuroscience: ten years of progress. Annu Rev Psychol 63:129-151. CrossRef Medline

Milad MR, Quirk GJ, Pitman RK, Orr SP, Fischl B, Rauch SL (2007a) A role for the human dorsal anterior cingulate cortex in fear expression. Biol Psychiatry 62:1191-1194. CrossRef Medline

Milad MR, Wright CI, Orr SP, Pitman RK, Quirk GJ, Rauch SL (2007b) Recall of fear extinction in humans activates the ventromedial prefrontal cortex and hippocampus in concert. Biol Psychiatry 62:446-454. CrossRef Medline

Milad MR, Pitman RK, Ellis CB, Gold AL, Shin LM, Lasko NB, Zeidan MA, Handwerger K, Orr SP, Rauch SL (2009) Neurobiological basis of failure to recall extinction memory in posttraumatic stress disorder. Biol Psychiatry 66:1075-1082. CrossRef Medline 
Miskovic V, Keil A (2012) Acquired fears reflected in cortical sensory processing: a review of electrophysiological studies of human classical conditioning. Psychophysiology 49:1230-1241. CrossRef Medline

Mueller EM, Makeig S, Stemmler G, Hennig J, Wacker J (2011) Dopamine effects on human error processing depend on catechol-O-methyltransferase VAL158MET genotype. J Neurosci 31:15818-15825. CrossRef Medline

Mueller EM, Burgdorf C, Chavanon ML, Schweiger D, Wacker J, Stemmler G (2013) Dopamine modulates frontomedial failure processing of agentic introverts versus extraverts in incentive contexts. Cogn Affect Behav Neurosci. Advance online publication. Retrieved Dec. 10, 2013. doi: 10.3758/ s13415-013-0228-9. CrossRef Medline

Mulert C, Jäger L, Schmitt R, Bussfeld P, Pogarell O, Möller HJ, Juckel G, Hegerl U (2004) Integration of fMRI and simultaneous EEG: towards a comprehensive understanding of localization and time-course of brain activity in target detection. Neuroimage 22:83-94. CrossRef Medline

Myers KM, Davis M (2007) Mechanisms of fear extinction. Mol Psychiatry 12:120-150. CrossRef Medline

Narayanan V, Heiming RS, Jansen F, Lesting J, Sachser N, Pape HC, Seidenbecher T (2011) Social defeat: impact on fear extinction and amygdalaprefrontal cortical $\theta$ synchrony in 5-HTT deficient mice. PLoS One 6:e22600. CrossRef Medline

Norberg MM, Krystal JH, Tolin DF (2008) A meta-analysis of D-cycloserine and the facilitation of fear extinction and exposure therapy. Biol Psychiatry 63:1118-1126. CrossRef Medline

Orsini CA, Kim JH, Knapska E, Maren S (2011) Hippocampal and prefrontal projections to the basal amygdala mediate contextual regulation of fear after extinction. J Neurosci 31:17269-17277. CrossRef Medline

Panitz C, Wacker J, Stemmler G, Mueller EM (2013) Brain-heart coupling at the P300 latency is linked to anterior cingulate cortex and insula: a cardio-electroencephalographic covariance tracing study. Biol Psychol 94:185-191. CrossRef Medline

Pape HC, Narayanan RT, Smid J, Stork O, Seidenbecher T (2005) $\theta$ activity in neurons and networks of the amygdala related to long-term fear memory. Hippocampus 15:874-880. CrossRef Medline

Pascual-Marqui RD, Michel CM, Lehmann D (1994) Low resolution electromagnetic tomography: a new method for localizing electrical activity in the brain. Int J Psychophysiol 18:49-65. CrossRef Medline

Pascual-Marqui RD, Lehmann D, Koenig T, Kochi K, Merlo MC, Hell D, Koukkou M (1999) Low resolution brain electromagnetic tomography (LORETA) functional imaging in acute, neuroleptic-naive, first-episode, productive schizophrenia. Psychiatry Res 90:169-179. CrossRef Medline

Phelps EA, Delgado MR, Nearing KI, LeDoux JE (2004) Extinction learning in humans: role of the amygdala and vmPFC. Neuron 43:897-905. CrossRef Medline
Pizzagalli DA, Greischar LL, Davidson RJ (2003) Spatio-temporal dynamics of brain mechanisms in aversive classical conditioning: high-density event-related potential and brain electrical tomography analyses. Neuropsychologia 41:184-194. CrossRef Medline

Pizzagalli DA, Oakes TR, Fox AS, Chung MK, Larson CL, Abercrombie HC, Schaefer SM, Benca RM, Davidson RJ (2004) Functional but not structural subgenual prefrontal cortex abnormalities in melancholia. Mol Psychiatry 9:393-405. CrossRef Medline

Pizzagalli DA, Peccoralo LA, Davidson RJ, Cohen JD (2006) Resting anterior cingulate activity and abnormal responses to errors in subjects with elevated depressive symptoms: a 128-channel EEG study. Hum Brain Mapp 27:185-201. CrossRef Medline

Quirk GJ, Mueller D (2008) Neural mechanisms of extinction learning and retrieval. Neuropsychopharmacology 33:56-72. CrossRef Medline

Santini E, Quirk GJ, Porter JT (2008) Fear conditioning and extinction differentially modify the intrinsic excitability of infralimbic neurons. J Neurosci 28:4028-4036. CrossRef Medline

Seidenbecher T, Laxmi TR, Stork O, Pape HC (2003) Amygdalar and hippocampal $\theta$ rhythm synchronization during fear memory retrieval. Science 301:846-850. CrossRef Medline

Shackman AJ, Salomons TV, Slagter HA, Fox AS, Winter JJ, Davidson RJ (2011) The integration of negative affect, pain and cognitive control in the cingulate cortex. Nat Rev Neurosci 12:154-167. CrossRef Medline

Sotres-Bayon F, Sierra-Mercado D, Pardilla-Delgado E, Quirk GJ (2012) Gating of fear in prelimbic cortex by hippocampal and amygdala inputs. Neuron 76:804-812. CrossRef Medline

Vidal-Gonzalez I, Vidal-Gonzalez B, Rauch SL, Quirk GJ (2006) Microstimulation reveals opposing influences of prelimbic and infralimbic cortex on the expression of conditioned fear. Learn Mem 13:728-733. CrossRef Medline

Vitacco D, Brandeis D, Pascual-Marqui R, Martin E (2002) Correspondence of event-related potential tomography and functional magnetic resonance imaging during language processing. Hum Brain Mapp 17:412. CrossRef Medline

Vogt BA (2005) Pain and emotion interactions in subregions of the cingulate gyrus. Nat Rev Neurosci 6:533-544. CrossRef Medline

Vogt BA, Pandya DN (1987) Cingulate cortex of the rhesus monkey: II. Cortical afferents. J Comp Neurol 262:271-289. CrossRef Medline

Wessa M, Flor H (2007) Failure of extinction of fear responses in posttraumatic stress disorder: evidence from second-order conditioning. Am J Psychiatry 164:1684-1692. CrossRef Medline

Zumsteg D, Friedman A, Wennberg RA, Wieser HG (2005) Source localization of mesial temporal interictal epileptiform discharges: correlation with intracranial foramen ovale electrode recordings. Clin Neurophysiol 116:2810-2818. CrossRef Medline 